\title{
Multidetector Computed Tomography Evaluation of Juvenile Nasopharyngeal Angiofibroma
}

\author{
${ }^{1}$ Nayana R Somayaji, ${ }^{2}$ Rahul Talwade, ${ }^{3}$ Anil K Shukla, ${ }^{4}$ V Seetha Pramila, ${ }^{5} \mathrm{R}$ Nagesh, ${ }^{6} \mathrm{GU}$ Pravin
}

\begin{abstract}
Juvenile nasopharyngeal angiofibroma is relatively uncommon accounting for $0.5 \%$ of all head and neck tumors occurring exclusively in adolescent males. It is a microscopically benign, yet locally aggressive tumor with high rates of recurrence and results in severe morbidity. Diagnosis requires high index of suspicion as it mimics other sinonasal conditions, like sinonasal polyp, neurofibroma, nasopharyngeal carcinoma, etc. A case of 14-year-old boy with history of swelling in the right cheek, bilateral nasal obstruction, epistaxis, and watering from right eye referred for multidetector computed tomography is reported in this study.
\end{abstract}

Keywords: Juvenile nasopharyngeal angiofibroma, Multidetector computed tomography, Nasal obstruction, Pterygopalatine fossa, Sinonasal polyp.

How to cite this article: Somayaji NR, Talwade R, Shukla AK, Pramila VS, Nagesh R, Pravin GU. Multidetector Computed Tomography Evaluation of Juvenile Nasopharyngeal Angiofibroma. J Med Sci 2016;2(2):38-41.

Source of support: Nil

Conflict of interest: None

\section{INTRODUCTION}

Juvenile nasopharyngeal angiofibroma (JNA) is a benign, vascular, and fibrous neoplasm arising in the nasopharynx accounting for $0.5 \%$ of all head and neck tumors. It almost always occurs exclusively in adolescent males. The tumor exhibits a strong tendency to bleed and frequently exhibits destructive and aggressive behavior. ${ }^{1,2}$ It was Hippocrates who first described it in the 5th century вс. However, Friedberg first used the term angiofibroma in 1940. The diagnosis of this condition requires a high index of suspicion as it mimics other sinonasal conditions and approaching it as such may result in fatal outcome. ${ }^{2}$ We present a case of JNA and discuss the steps necessary for radiological diagnosis using multidetector computed tomography (MDCT).

\footnotetext{
${ }^{1,2}$ Postgraduate Student and Trainee, ${ }^{3-6}$ Professor

${ }^{1-3,5,6}$ Department of Radiodiagnosis, RajaRajeswari Medical College and Hospital, Bengaluru, Karnataka, India

${ }^{4}$ Department of Radiodiagnosis, ACS Medical College and Hospital, Chennai, Tamil Nadu, India

Corresponding Author: Nayana R Somayaji, Postgraduate Student and Trainee, Department of Radiodiagnosis RajaRajeswari Medical College and Hospital, Bengaluru Karnataka, India, e-mail: somayaji.nayana@gmail.com
}

\section{CASE REPORT}

A 14-year-old boy presented with complaints of swelling in right cheek since 1 month, which progressively increased in size (Fig. 1). Patient also complained of bilateral nasal obstruction with history of 3 to 4 episodes of epistaxis in the last month. Patient gave history of watering from right eye. On examination, right nasal cavity showed an ulcerative growth with dilated blood vessels and serosanguinous discharge along with a swelling involving the right buccal mucosa extending to the soft and hard palate (Fig. 2). Patient was referred to the Department of Radiology for MDCT.

We used a 128 slice Siemens Perspective CT machine and images obtained at submillimeter sections in the

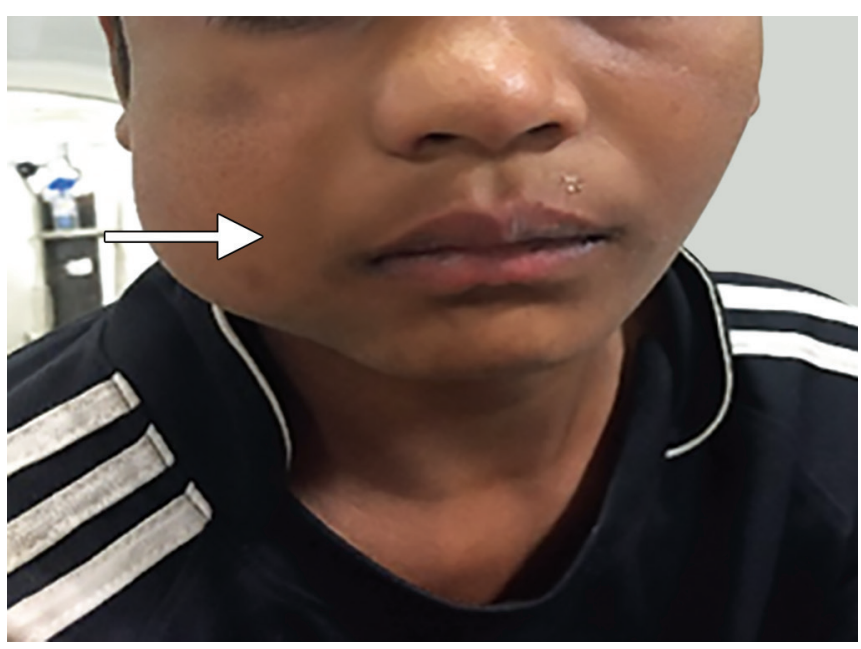

Fig. 1: Fourteen-year-old boy with swelling in right cheek

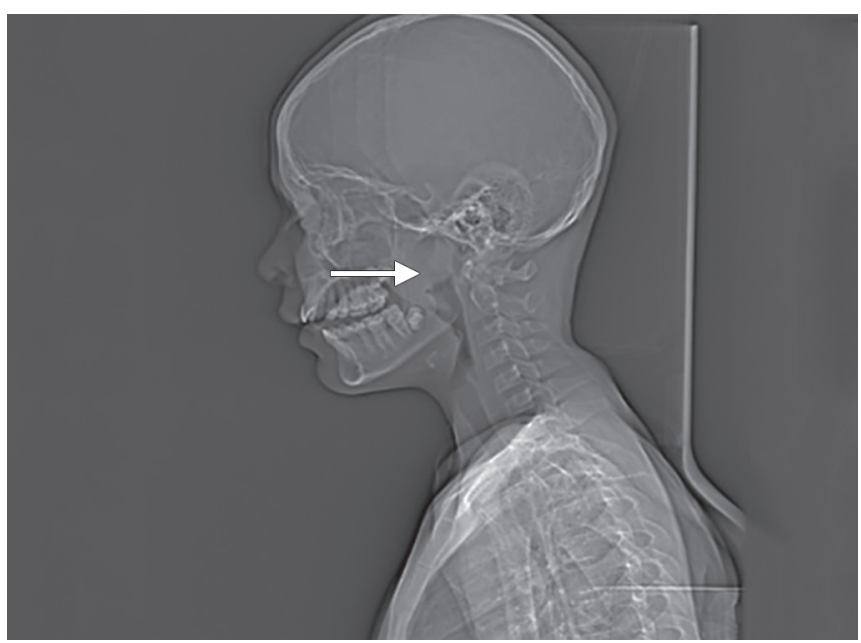

Fig. 2: Multidetector CT showing topogram soft tissue opacity 


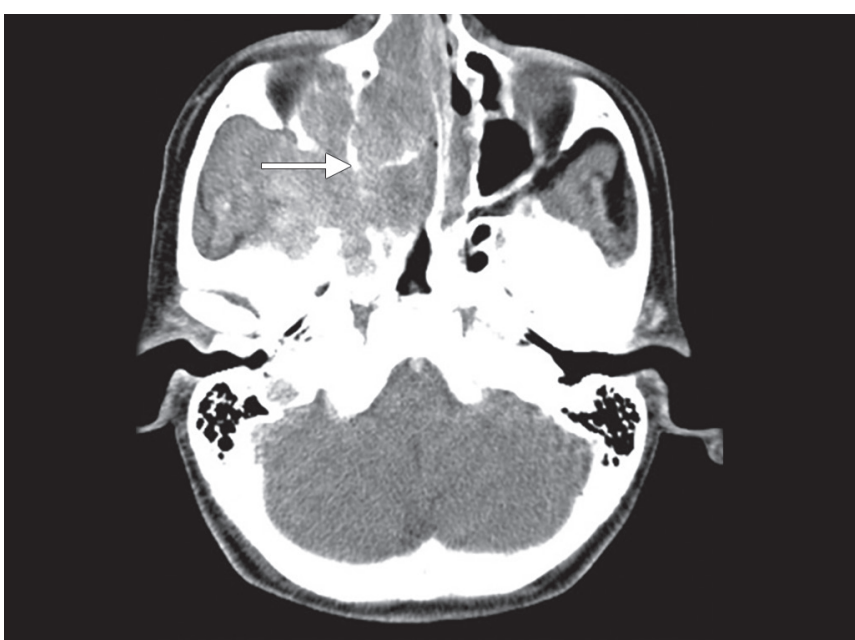

Fig. 3: Multidetector CT arterial phase - axial section showing uniformly enhancing mass lesion involving the right side nasal cavity, nasopharynx, maxillary sinus, pterygopalatine fossa

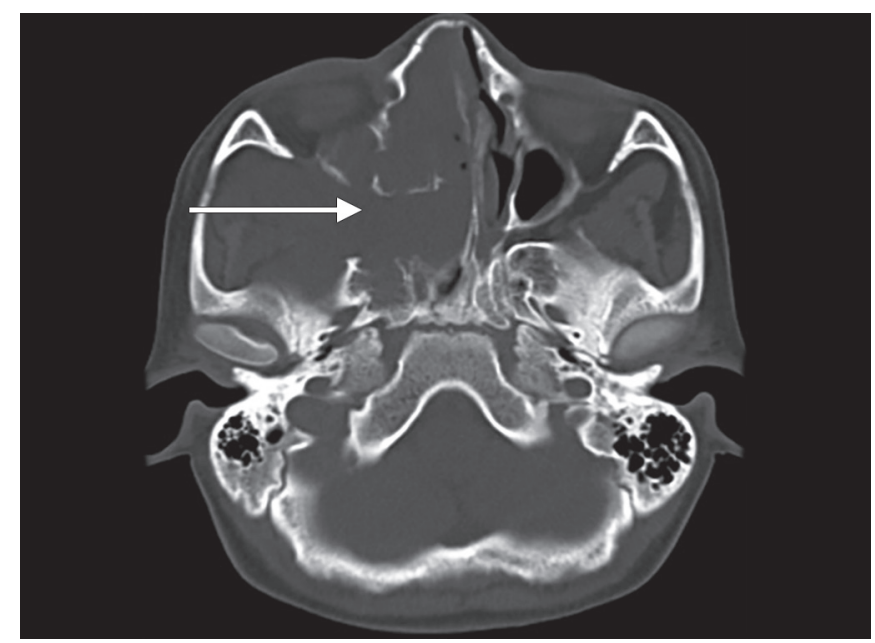

Fig. 5: Multidetector CT bone window - obliteration of the right side osteomeatal complex, pterygomaxillary fissure, and pterygopalatine fossa

axial, coronal, and sagittal planes before and after contrast medium injection revealed a large, ill-defined, solid, uniformly enhancing mass lesion measuring $6.1 \times 5.3 \times$ $6.6 \mathrm{~cm}(\mathrm{TR} \times \mathrm{AP} \times \mathrm{CC})$ involving the right side nasal cavity, nasopharynx, maxillary sinus, pterygopalatine fossa extending antero-laterally up to the subcutaneous plane of the cheek and posteriorly to the sphenoid sinus (Figs 2 to 4 ). The lesion is causing obliteration of the right side osteomeatal complex, pterygomaxillary fissure, and pterygopalatine fossa with mild obliteration of the right optic canal (Figs 5 and 6). The lesion is also causing all on the ride side, erosion of the coronoid process of the mandible, anterior and lateral wall of maxillary antrum, medial and lateral plate of pterygoid process, lamina papyracea, middle and inferior turbinates, and inferior orbital fissure (Figs 6 and 7). There was deviated nasal septum with convexity to the left with bony erosions.

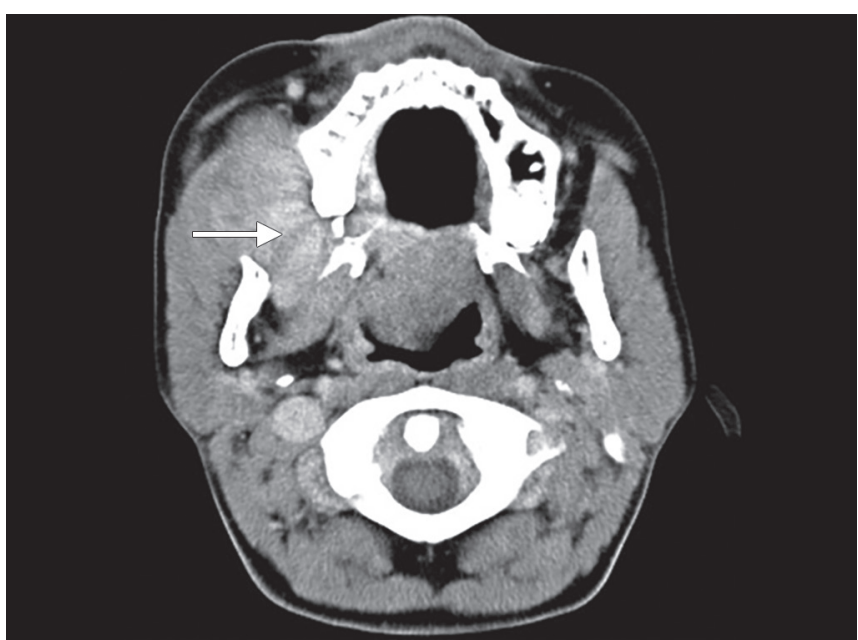

Fig. 4: Multidetector CT venous phase - axial section the lesion extending up to the right cheek. Jugular vein is prominent

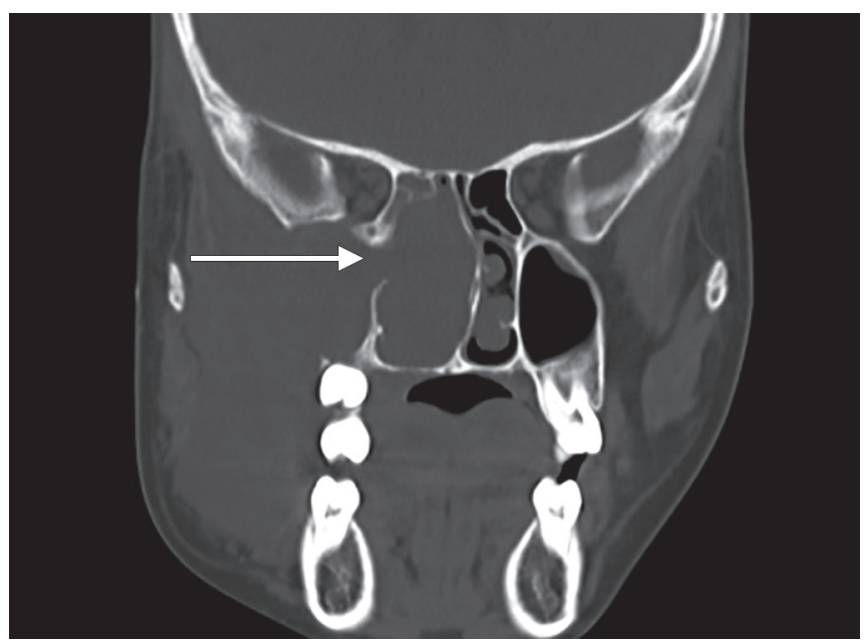

Fig. 6: Coronal image in bone window - lesion causing obliteration of the right osteomeatal complex with erosion of anterior and lateral wall of maxillary antrum, medial and lateral plate of pterygoid process, lamina papyracea, middle and inferior turbinates

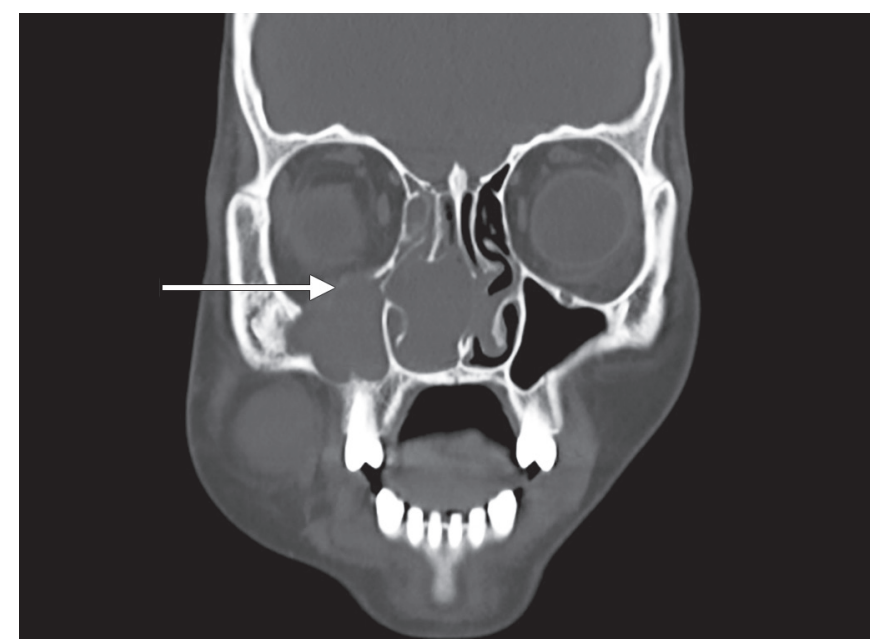

Fig. 7: Coronal image in bone window showing the lesion causing erosion of the inferior orbital fissure 
Right jugular vein was prominent (Fig. 4). There was no calcification, cervical lymphadenopathy, or intracranial extension. Finally, an impression of a large solid rightsided nasopharyngeal mass with diagnosis of JNA (Grade II C) was given.

\section{DISCUSSION}

Hippocrates described the tumor in the 5th century $\mathrm{BC}$, but it was Friedberg who first used the term angiofibroma in $1940 .^{1}$ As the name implies, JNA is a disease of the young and occurs almost exclusively in adolescent males between the ages of 5 and 25 with a mean age of 15 years. $^{2}$ The high prevalence in males can probably be explained by various genetic studies, which show a close relation between these angiomas and androgen receptor expression, indicating the tumor could be androgen dependant. $^{3}$

Juvenile nasopharyngeal angiofibroma is known to arise in the area of sphenopalatine foramen and pterygopalatine fossa with a tendency to extend to adjacent anatomical sites like nasopharynx medially, sphenopalatine, and infratemporal fossa extending up to the cheek laterally, internal carotid artery, maxillary nerve inferior orbital fissure posteriorly.

Typically, the tumor is highly vascular receiving its blood supply from the internal maxillary artery. Other known vessels include the ascending pharyngeal artery as well as the external, internal, and common carotid arteries. Since some studies show that $36 \%$ of the cases exhibit bilateral vascular system involvement, it is important to study bilateral carotid systems. Biopsy of JNA can result in massive hemorrhage, hence should be avoided. ${ }^{2,4}$

Histopathologically, features of vascularity and fibroblasts are seen. Fibroblasts are plump, ovoid to spindle shaped, with excessive amount of connective tissue. Blood vessels lined by plump endothelial cells with no muscle or elastic features are found in the stroma. This lack of muscle, elastic fibers is the cause for massive hemorrhage even with slight manipulation at the tumor site. ${ }^{5}$

Patients typically present with progressive nasal obstruction (80-90\%), recurrent epistaxis (40\%), swelling of the cheek as seen in this case report. Headache and facial pain may arise due to involvement of para nasal sinuses. Chronic otomastoiditis, hearing loss may occur due to involvement of the Eustachian tube. When orbit is involved, patients complain of watering of eye, proptosis. Advanced lesions may show cranial nerve involvement. ${ }^{2,4}$

Diagnosis should ideally be aided by contrast enhanced computed tomography (CT) to recognize the origin, extensions as well as pattern of vascularity of the lesion. About $96 \%$ of JNA arises from the pterygopalatine fossa with the lesion showing homogenous enhancement post contrast. $^{4}$

A study by Atalar ${ }^{1}$ in a group of 72 patients showed three characteristic, consistent findings that suggest a diagnosis of JNA. These are:

1. A soft tissue component in the nasopharynx or nasal cavity, with or without extension to contralateral site

2. A soft tissue component in the pterygopalatine fossa

3. Erosion of posterior osseous margin of the sphenopalatine foramen extending to the base of the medial pterygoid plate. In our case, the lesion was located in the nasopharynx, and projected into the right sphenoid sinus. ${ }^{1}$

Multidetector CT is a crucial preoperative test as it accurately shows the erosion of bony structures and widening of foramen and fissures at the base of the skull. It also helps in assessing intracranial extension, thus determining the need for aggressive surgical removal of the tumor.

The differential diagnosis of JNA includes:

- Sinonasal polyp: Located toward ostium/hardly extend to the nasopharynx, elderly age, less vascularity

- Neurofibroma: Well defined, with minimal, or no contrast enhancement.

- Malignant neoplasms like nasopharyngeal carcinoma centered around fossa of Rosenmüller shows heterogenous enhancement post contrast associated with cervical lymphadenopathy. ${ }^{1}$

Classification for staging of the tumor was first introduced by Sessions in 1981. Over the years, several staging systems have been adapted by many authors like Fisch, Chandler, and Andrews. The staging system introduced by Radkowski is widely used in practice as it emphasizes on the tendency of posterior extension of the tumor to the pterygoid plates (Table 1). It also includes the erosion of skull base, thus helping in radiological grading of JNA. ${ }^{4}$

Table 1: Radkowski JNA classification system

\begin{tabular}{ll}
\hline Stage & Features \\
\hline IA & Limited to nose or nasopharynx \\
IB & Extension into at least one paranasal sinus \\
IIA & $\begin{array}{l}\text { Minimal extension through sphenopalatine foramen, } \\
\text { includes minimal part of medial pterygopalatine fossa }\end{array}$ \\
IIB $\quad \begin{array}{l}\text { Full occupation of pterygopalatine fossa with Holman- } \\
\text { Miller sign, lateral, or anterior displacement of maxillary } \\
\text { artery branches. May have superior extension with } \\
\text { orbital bone erosion }\end{array}$ \\
IIC $\quad \begin{array}{l}\text { Extension into pterygomaxillary fossa into cheek, } \\
\text { temporal fossa, or posterior pterygoids }\end{array}$ \\
IIIA $\quad \begin{array}{l}\text { Skull base erosion with minimal intracranial extension } \\
\text { IIIB } \quad \text { Skull base erosion with extensive intracranial extension } \pm \\
\text { cavernous sinus }\end{array}$ \\
\hline
\end{tabular}




\section{CONCLUSION}

Juvenile nasopharyngeal angiofibroma is a rare, vascular, locally invasive benign tumor with high recurrence exclusively occurring in adolescent boys. Typical presentation includes nasal obstruction, stuffiness, and recurrent epistaxis. Characteristic signs on radiologic imaging modalities help to confirm diagnosis as biopsy stands the risk of fatal hemorrhage. Our case exhibits lesion extending into pterygomaxillary fossa and the right cheek, hence diagnosis of JNA with Grade II C (Radkowski classification) was made.

\section{REFERENCES}

1. Atalar M, Solak O, Müderris S. Juvenıle nasopharyngeal angiofibroma: radiologic evaluation and pre-operative embolization. KBB Forum 2006;5(1):58-61.

2. Ikubor J, Okolugbo N, Okhakhu A. Radiological features of juvenile nasopharyngeal angiofibroma. J West Afr Coll Surg 2013 Oct-Dec;3(4):84-91.

3. Mishra S, Praveena NM, Panigrahi RG, Gupta YM. Imaging in the diagnosis of juvenile nasopharyngeal angiofibroma. J Clin Imaging Sci 2013 Mar;3(Suppl 1):1.

4. Nicolai P, Schreiber A, Bolzoni Villaret A. Juvenile angiofibroma: evolution of management. Int J Pediatr 2012;2012:412545.

5. Garça MF, Yuca SA, Yuca K. Juvenile nasopharyngeal angiofibroma. Eur J Gen Med 2010;7:419-425. 